\title{
Action plans in patients presenting to emergency departments with asthma exacerbations: Frequency of use and description of contents
}

\author{
Elfriede Cross MD(c) ${ }^{1}$, Cristina Villa-Roel MD MSc PhD(c) ${ }^{1,4}$, Sumit R Majumdar MD MPH FRPC ${ }^{2}$, \\ Mohit Bhutani MD FRCPC FCCP2, Rhonda J Rosychuk PhD ${ }^{3}$, \\ Stephanie Couperthwaite BSc ${ }^{1}$, Brian H Rowe MD MSc CCFPEM FCCP1,4,5
}

E Cross, C Villa-Roel, SR Majumdar, et al. Action plans in patients presenting to emergency departments with asthma exacerbations: Frequency of use and description of contents. Can Respir J 2014;21(6):351-356.

BACKGROUND: Although underused, written asthma action plans (AAPs) are associated with reduced numbers of emergency department (ED) visits and hospitalizations.

OBJECTIVE: To describe the frequency of use and contents of any AAPs reported by patients presenting with exacerbations to three urban Canadian EDs.

METHODS: Prospective data were collected through ED interview and chart review. Descriptive analyses used proportions and medians with interquartile range; multivariable logistic regression was used for the adjusted analyses.

RESULTS: Among 176 enrolled patients, the median age was 27 years (interquartile range 23 to 39 years) and $97(55 \%)$ were female. Few ( $n=42$ [24\%]) reported having AAPs at ED presentation and only six were written. Most ( $\mathrm{n}=35[75 \%])$ patients with any AAP took action before the ED visit; none used a valid anti-inflammatory strategy. The first step of 27 plans was to increase asthma medication; no patients appropriately increased inhaled corticosteroids (ICS). In multivariable analyses, only the use of either ICS or ICS/long-acting $\beta$-agonist combination agents (31\% had AAPs versus $12 \%$ did not have AAPs (adjusted OR 3.0 [95\% CI 1.14 to 8.07$]$ ) and asthma education (47\% had AAPs versus $21 \%$ did not have AAPs, adjusted OR 3.2 [95\% CI 1.13 to 9.19]) were independently associated with AAP possession.

CONCLUSION: Possession of AAPs among patients presenting to the ED with acute asthma was low, and only one in 10 AAPs were written. Patients who reported having any AAP used ineffective strategies to abort or mitigate the severity of an ED visit. Increasing frequency of written AAPs and improving their contents holds immediate promise in improving outcomes related to asthma.

Key Words: Acute asthma; Asthma education; Care gaps; Prevention

$A$ pproximately $10 \%$ of the population of North America has A asthma, and the prevalence of this condition has been increasing in recent years $(1,2)$. Patients with asthma frequently present to the emergency department (ED) with exacerbations that may result in potentially serious complications and relapses $(3,4)$. Internationally, strategies for avoiding, mitigating and treating exacerbations have been developed and recommended (5-8).

Patients seen in the ED for asthma exacerbations should be encouraged to see their primary care provider (PCP) or specialist for follow-up, adjustment of asthma medications, reassessment and reinforcement of self-management strategies $(5,9)$. Written asthma action plans (AAPs) are one of the key strategies for ambulatory asthma care, and involve self-monitoring and response to therapy based on symptoms or close monitoring of peak flow readings $(10-12)$. Systematic reviews have shown that written AAPs, as part of self-management, are effective
Les plans d'action pour les patients qui se rendent à l'urgence à cause d'exacerbations de l'asthme : la fréquence d'utilisation et la description du contenu

HISTORIQUE : Même s'ils sont sous-utilisés, les plans d'action contre l'asthme (PAA) écrits s'associent à une diminution du nombre de consultations à l'urgence et d'hospitalisations.

OBJECTIF : Décrire la fréquence d'utilisation et le contenu des PAA déclarés par les patients qui ont consulté à cause d'une exacerbation dans trois urgences canadiennes en milieu urbain.

MÉTHODOLOGIE : Des chercheurs ont colligé des données prospectives par des entrevues à l'urgence et des examens de dossiers. Les analyses descriptives faisaient appel à des proportions et à des médianes accompagnées d'un intervalle interquartile. La régression logistique multivariable a été utilisée pour les analyses rajustées.

RÉSULTATS : Les 176 patients participants, dont 97 femmes (55\%), avaient un âge médian de 27 ans (intervalle interquartile de 23 à 39 ans). Quelques-uns ( $\mathrm{n}=42$ [24\%]) ont déclaré avoir un PAA lors de leur consultation à l'urgence, mais seulement six étaient écrits. La plupart des patients $(\mathrm{n}=35[75 \%])$ qui avaient un PAA prenaient des mesures avant d'aller à l'urgence. Personne n'utilisait une stratégie anti-inflammatoire valide. La première étape des 27 plans consistait à accroître la médication contre l'asthme, mais aucun patient ne rajustait correctement ses corticostéroïdes inhalés (CSI). Dans les analyses multivariables, seules l'utilisation de CSI ou d'une polythérapie de CSI et de bêta-agonistes de longue durée (31\% avaient un PAA et $12 \%$ n'en avaient pas; RC rajusté 3,0 [95 \% IC 1,14 à $8,07]$ ) et l'éducation sur l'asthme (47\% avaient une PAA et $21 \%$ n'en avaient pas; RC rajusté 3,2 [95 \% IC 1,13 à 9,19]) s'associaient de manière indépendante à la possession d'un PAA.

CONCLUSION : Peu de patients possédaient un PAA lorsqu'ils consultaient à l'urgence à cause d'un asthme aigu, et seulement un sur dix était écrit. Les patients qui déclaraient avoir un PAA utilisaient des stratégies inefficaces pour éviter la consultation à l'urgence ou en atténuer la gravité. $\mathrm{Si}$ on rédige davantage de PAA et qu'on en bonifie le contenu, on peut espérer une amélioration immédiate de l'asthme.

in reducing the number of hospitalizations and $\mathrm{ED}$ visits due to acute asthma (13). Written AAPs have also been associated with improvement in medication adherence and health-related quality of life; furthermore, one study reported that patients with written AAPs were more satisfied with their asthma care $(13,14)$. On the other hand, verbal AAPs are largely ineffective $(12,13)$; in one study, the risk of death from asthma was four times lower with a written AAP than with a verbal AAP (15).

There are four main components to individualized written AAPs: triggers to increase therapy (based on symptoms or peak flow readings); strategies to increase therapy; the duration of increased therapy; and the 'tipping point' to seek additional medical help (12). Despite the aforementioned collective evidence of benefit, the use of written AAPs remains quite low, with $10 \%$ to $45 \%$ of patients reporting to have one $(14,16,17)$. Canadian data from an unbiased sample found

${ }^{1}$ Department of Emergency Medicine, ${ }^{2}$ Department of Medicine; ${ }^{3}$ Department of Pediatrics, Faculty of Medicine Eु Dentistry; ${ }^{4}$ School of Public Health, University of Alberta; ${ }^{5}$ Alberta Health Services, Edmonton, Alberta

Correspondence: Dr Brian H Rowe, Department of Emergency Medicine, University of Alberta, 1G1.43 Walter Mackenzie Health Sciences Centre, 8440-112 Street, Edmonton, Alberta T6G 2B7. Telephone 780-407-6761, fax 780-407-3982,

e-mail brian.rowe@ualberta.ca 
TABLE 1

Characteristics of patients presenting to an emergency department for asthma exacerbations

\begin{tabular}{lcc}
\hline \multirow{2}{*}{ Characteristic } & \multicolumn{2}{c}{ Asthma action plan } \\
\cline { 2 - 3 } Age, years, median (IQR) & $28(24,35)$ & $27(22,40)$ \\
Female sex & $25(59.5)$ & $72(53.7)$ \\
Ancestry & & \\
$\quad$ White & $21(50)$ & $66(49.2)$ \\
$\quad$ Nonwhite & $21(50)$ & $68(50.7)$ \\
Marital status & & \\
$\quad$ Single & $18(42.9)$ & $83(61.9)$ \\
$\quad$ Other & $24(57.1)$ & $51(38.0)$ \\
Education & & \\
$\quad$ Some high school & $18(42.9)$ & $64(47.8)$ \\
$\quad$ Other & $24(57.1)$ & $70(52.2)$ \\
Occupation during the past year & & \\
$\quad$ Working for pay or profit & $33(78.6)$ & $93(69.4)$ \\
Other & $9(21.4)$ & $41(30.6)$ \\
\hline
\end{tabular}

Data presented as $n(\%)$ unless otherwise indicated. IQR Interquartile range $\left(P_{75}, P_{25}\right)$

that $22 \%$ of physicians report providing AAPs to patients with asthma, and $11 \%$ of patients with asthma report receiving a written AAP (18). Barriers to the uptake of written AAPs include lack of adequate time for clinicians to produce and explain them to their patients, lack of experience and confidence in completing written AAPs, low awareness of their importance, and variations in both content and structure (eg, visual design, usability) $(19,20)$. Previous research has mostly reported on stable patients, often in the primary care setting. There are limited data regarding care gaps related to asthma control and management, and written AAP uptake in patients presenting to EDs with asthma exacerbations (21).

The aim of the present study was to describe the frequency of use, content and potential correlates of the use of any AAPs by patients presenting to the ED and who are safely discharged after being treated for acute asthma.

\section{METHODS}

Study design and population

The present study was a secondary analysis of data obtained from two studies conducted in Edmonton, Alberta (one randomized controlled trial [NCT01107613] and one prospective, randomized, open-label study [NCT01079000]). Prospective data used for the present study were obtained from identical standardized baseline questionnaires and a medical chart review of patients 17 to 55 years of age who were treated for an asthma exacerbation and before being discharged back to the community. Screening and data collection were performed on a daily basis by trained research staff. Patients $>55$ years of age, individuals with chronic obstructive pulmonary disease or another end-stage lung disease, and those with an inability to consent were excluded.

\section{Study variables}

Sociodemographic data (eg, age, sex, race [visual assessment]), marital status, level of education and occupation) were considered for the present analysis. Chronic asthma factors, preventive factors and health care utilization were also explored. Finally, information regarding patient characteristics at ED presentation, concurrent medication, ED management and discharge plan were described.

\section{AAP-related measurements}

AAPs that exclusively involved home remedies, those not involving the use of medication, peak flow/symptom monitoring or seeking additional medical attention $(n=5)$, were excluded from the present analysis. One of two clinician-investigators (CV-R, BHR) independently reviewed the enrollment data and adjudicated patients' report and use of AAPs, and the presence of other gaps in asthma care (eg, availability of a PCP, use of spacer devices, influenza vaccination, cigarette smoking, asthma medication use and adherence, and asthma education). Agreement was assessed by comparing the first 50 cases and an ongoing random $10 \%$ sample of cases thereafter; differences were resolved through consensus. Finally, a third reviewer (EC) examined every record to document the content of each AAP and the actions taken before the ED presentations. Percentage of agreement between investigators regarding the care gaps adjudication was measured and inter-rater agreement was calculated based on the kappa statistic.

\section{Statistical analysis}

De-identified baseline data were appended and verified for consistency using the original data sources. Descriptive data include counts and proportions, or medians with interquartile range $\left(\mathrm{P}_{75}, \mathrm{P}_{25}\right)$ as appropriate. Baseline comparisons based on having or not having any AAP at the ED presentation were performed using $\chi^{2}$ tests for categorical variables and Mann-Whitney $U$ tests for continuous variables. Multivariable logistic regression analyses were used to determine the independent association between having an AAP (either written or verbal) and variables identified at $\mathrm{P}<0.05$ significance in the univariate comparisons and those deemed to be of clinical importance (eg, age, sex, Canadian Triage Acuity Scale [CTAS] score). Given that the reported use of AAPs was low, a parsimonious final modelling strategy was used with the aim of having no more than five or six variables (clinically significant: previous admissions to the intensive care unit [ICU], previous exposure to asthma education, and concurrent use of either inhaled corticosteroids [ICS] or ICS/long-acting beta-agonists [LABAs] combination agents; and forced due to clinical significance: age, sex, CTAS score) to prevent over-fitting. All analyses were performed using Stata version 11 (StataCorp, USA) .

\section{Ethical considerations}

The Health Ethics Research Board at the University of Alberta (Edmonton, Alberta) granted ethics approval for the primary studies. All patients provided informed written consent; additional consent was not required for the present secondary analysis.

\section{RESULTS}

Sociodemographic and clinical characteristics

A total of 176 patients were included in the present analysis; all patients who were approached and provided informed consent completed the study questionnaires. The median age of the study population was 27 years (interquartile range 23, 39), 97 (55\%) were female and one-half $(49 \%)$ were white. Tables 1 to 3 summarize data regarding sociodemographics, chronic asthma factors and ED course.

\section{AAPs}

Forty-seven (27\%) patients reported having an AAP that they used in case of worsening symptoms, $42(24 \%)$ were potentially appropriate AAPs and six (14\%) were written AAPs (Figure 1). There was no charted evidence of AAP delivery at discharge by treating ED physicians in this sample.

In general, univariate analyses revealed that patients with an AAP had received more asthma education ( $47 \%$ versus $21 \% ; \mathrm{P}=0.004$ ), experienced more previous ED visits for acute asthma (29\% versus 5\%; $\mathrm{P}=0.003$ ), more admissions to the ICU ( $43 \%$ versus $21 \% ; \mathrm{P}=0.05$ ), and greater concurrent use of either ICS or ICS/LABA combination agents $(31 \%$ versus $12 \% ; \mathrm{P}=0.005)$ than patients with no AAPs.

\section{Description of AAP}

The agreement between the independent adjudicators in the first 50 cases was $86 \%$, followed by perfect agreement on the subsequent $10 \%$ random sample (simple agreement $=100 \%$; $\mathrm{kappa}=1.0$ ). Among the 42 patients with AAPs, the first step of 27 (64\%) plans was to increase asthma medication; in eight (19\%) plans, asthma medications were increased as a second-line treatment for worsening 
TABLE 2

Comparison of chronic asthma factors and health system utilization of patients discharged from the emergency department (ED) for asthma exacerbations who reported having an asthma action plan (AAP) versus those who did not

\begin{tabular}{|c|c|c|}
\hline & $\begin{array}{l}\text { With AAP } \\
(n=42)\end{array}$ & $\begin{array}{l}\text { No AAP } \\
(n=134)\end{array}$ \\
\hline \multicolumn{3}{|l|}{ Chronic asthma factors } \\
\hline Previous diagnosis of asthma & $42(100)$ & $129(96.3)$ \\
\hline $\begin{array}{l}\text { Time since asthma diagnosis, years, } \\
\text { median (IQR) }\end{array}$ & $21(15,26)$ & $17(11,23)$ \\
\hline Been intubated due to acute asthma & $5(11.9)$ & $17(12.7)$ \\
\hline Intensive care unit admission for asthma* & $9(21.4)$ & $12(8.9)$ \\
\hline \multicolumn{3}{|l|}{ Preventive factors } \\
\hline Has a family physician & $28(66.7)$ & $101(75.4)$ \\
\hline Saw family physician in past 2 years & $5(17.9)$ & $8(8.8)$ \\
\hline Not documented & $23(82.1)$ & $93(92.1)$ \\
\hline $\begin{array}{l}\text { Seeing a respirologist frequently for } \\
\text { asthma care }\end{array}$ & $2(4.8)$ & $0(0)$ \\
\hline Has an inhaler & $42(100)$ & $114(85.1)$ \\
\hline $\begin{array}{l}\text { Has an aerochamber if patient has } \\
\text { an inhaler }\end{array}$ & $20(47.6)$ & $41(35.9)$ \\
\hline Received asthma education* & $9(21.4)$ & $10(7.5)$ \\
\hline Ever had a flu vaccine & $13(30.9)$ & $49(36.6)$ \\
\hline \multicolumn{3}{|l|}{ Smoking status } \\
\hline Never & $26(61.9)$ & $66(49.2)$ \\
\hline Current & $10(23.8)$ & $38(28.4)$ \\
\hline Pack-years, median (IQR) & $7(3,13)$ & $3(1,8)$ \\
\hline Previous & $6(14.3)$ & $30(22.4)$ \\
\hline Pack-years, median (IQR) & $6(5,18)$ & $7(2,11)$ \\
\hline \multicolumn{3}{|l|}{ Body mass index, $\mathrm{kg} / \mathrm{m}^{2}$} \\
\hline$\leq 19.9$ & $2(4.8)$ & $11(8.2)$ \\
\hline $20-24.9$ & $20(47.6$ & $41(30.6$ \\
\hline$\geq 25$ & $20(47.6$ & $75(55.9$ \\
\hline Not documented & $0(0)$ & $7(5.2)$ \\
\hline \multicolumn{3}{|l|}{ Health system utilization } \\
\hline \multicolumn{3}{|l|}{ Provision of routine asthma care } \\
\hline By family physician & $19(45.2)$ & $48(35.8)$ \\
\hline In the ED & $13(30.9)$ & $53(39.5)$ \\
\hline In walk-in clinics & $10(23.8)$ & $23(17.2)$ \\
\hline \multicolumn{3}{|l|}{ Acute asthma care } \\
\hline Has had previous ED visits for asthma* & $40(95.2)$ & $99(73.9)$ \\
\hline Visited ED for asthma in past 2 years & $19(74.5)$ & $51(53.7)$ \\
\hline $\begin{array}{l}\text { Time since last ED visit for acute asthma, } \\
\text { years, median (IQR) }\end{array}$ & $1(0.3,4)$ & $2(0.3,7)$ \\
\hline
\end{tabular}

Data presented as $n(\%)$ unless otherwise indicated. ${ }^{*} P \leq 0.05$ in the univariate analyses. IQR Interquartile range $\left(P_{75}, P_{25}\right)$

asthma. In addition, 12 of the 35 that recommended any increase at all increased their short-acting beta-agonist medication without increasing ICS. Only four patients reported doubling or tripling their controller medication dose, and no patients reported quadrupling or quintupling the ICS dose to prevent an asthma exacerbation. Interestingly, specific anti-inflammatory agents were never reported. Twelve AAPs consisted of home remedies as a first step for worsening asthma. Additional details regarding the AAP components are shown in Table 4. More than three-quarters (83\%) of those with an AAP reported specific actions before presenting to the ED. The most common actions taken before presenting to the ED were an increase in medication (either only short-acting beta-agonist, ICS or combination $[\mathrm{n}=19]$ ) or home remedies (alone or in addition to medication [ $\mathrm{n}=9]$ ).

In multivariable analyses, after adjusting for age (transformed variable due to non-normal distribution), sex, CTAS score and previous ICU admission, the use of either ICS or ICS/LABA combination
TABLE 3

Course and management of patients discharged from an emergency department (ED) following asthma exacerbations with and without an asthma action plan (AAP)

\begin{tabular}{|c|c|c|}
\hline & With AAP $(n=42)$ & No AAP $(n=134)$ \\
\hline \multicolumn{3}{|l|}{ ED presentation } \\
\hline \multicolumn{3}{|c|}{ Canadian Triage and Acuity Scale score } \\
\hline 1 and 2 & $12(28.6)$ & $21(15.7)$ \\
\hline 3 & $27(64.3)$ & $88(65.7)$ \\
\hline 4 and 5 & $3(7.1)$ & $25(18.7)$ \\
\hline \multicolumn{3}{|l|}{ Most common symptoms } \\
\hline Shortness of breath & $42(100)$ & $129(96.3)$ \\
\hline Cough & $37(88.1)$ & $116(86.6)$ \\
\hline Wheezing & $38(90.5)$ & $111(82.8)$ \\
\hline EMS arrival & $3(7.1)$ & $7(5.2)$ \\
\hline Used $\beta$-agonist puffs in past $24 \mathrm{~h}$ & $37(88.1)$ & $90(67.2)$ \\
\hline Puffs, median (IQR) & $15(8,20)$ & $8(4,14)$ \\
\hline \multicolumn{3}{|l|}{ Vital signs, median (IQR) } \\
\hline Heart rate, beats/min & $102(90,11)$ & $95(82,106)$ \\
\hline Respiratory rate, breaths/min & $22(20,26)$ & $20(18,24)$ \\
\hline $\mathrm{SaO}_{2}$ (on room air) & $97(95,98)$ & $97(96,98)$ \\
\hline Temperature, ${ }^{\circ} \mathrm{C}$ & $36.6(36.2,36.8)$ & $36.6(36.3,36.8)$ \\
\hline \multicolumn{3}{|c|}{ Asthma medications at ED presentation } \\
\hline Short-acting $\beta$-agonist & $40(95.2)$ & $109(81.3)$ \\
\hline No ICS & $8(19)$ & $46(34.3)$ \\
\hline On ICS alone & $10(23.8)$ & $23(17.2)$ \\
\hline $\begin{array}{l}\text { On combination agents alone } \\
\text { (ICS/LABA) }\end{array}$ & $19(45.2)$ & $47(35.1)$ \\
\hline On either ICS or ICS/LABA* & $34(81)$ & $74(55.2)$ \\
\hline Anticholinergics & $3(7.1)$ & $6(4.8)$ \\
\hline Prednisone & $3(7.1)$ & $5(3.7)$ \\
\hline No asthma medication & $0(0)$ & $21(15.7)$ \\
\hline \multicolumn{3}{|l|}{ ED management } \\
\hline Received inhaled $\beta$-agonists & $38(90.5)$ & $127(94.8)$ \\
\hline $\begin{array}{l}\text { Received inhaled anticholinergic } \\
\text { agents }\end{array}$ & $31(73.8)$ & $111(82.8)$ \\
\hline Received systemic corticosteroids & $32(76.2)$ & $106(79.1)$ \\
\hline Antibiotics & $2(4.8)$ & $8(5.9)$ \\
\hline \multicolumn{3}{|l|}{ Lung function, median (IQR) } \\
\hline Earliest PEF $(n=152)$ & $250(214,350)$ & $280(205,350)$ \\
\hline$\%$ predicted & $60(41,71)$ & $53(44,71)$ \\
\hline Predischarge PEF $(n=175)$ & $327(270,377)$ & $352(297,439)$ \\
\hline$\%$ predicted & $69(61,81)$ & $71(57,88)$ \\
\hline Change in \% predicted PEFR & $10(0,26)$ & $14(2,27)$ \\
\hline \multicolumn{3}{|c|}{ Asthma medications at ED discharge } \\
\hline Short-acting $\beta$-agonist & $40(95.2)$ & $122(91)$ \\
\hline Not on ICS & $3(7.1)$ & $21(15.7)$ \\
\hline On ICS alone & $14(33.3)$ & $54(40.3)$ \\
\hline On ICS/LABA agents & $20(47.6)$ & $49(36.6)$ \\
\hline On ICS or ICS/LABA agents & $39(92.9)$ & $113(84.3)$ \\
\hline Anticholinergic agents & $4(9.5)$ & $17(12.7)$ \\
\hline Prednisone & $40(95.2)$ & $118(88.1)$ \\
\hline Not discharged on any medication & $0(0)$ & $1(0.7)$ \\
\hline
\end{tabular}

Data presented as $n(\%)$ unless otherwise indicated. ${ }^{*} P \leq 0.05$ in the univariate analyses. EMS Emergency medical services; ICS Inhaled corticosteroids; IQR Interquartile range $\left(P_{75}, P_{25}\right)$; LABA Long-acting $\beta$-agonist; PEF Peak expiratory flow; PEFR PEF rate; $\mathrm{SaO}_{2}$ Oxygen saturation 


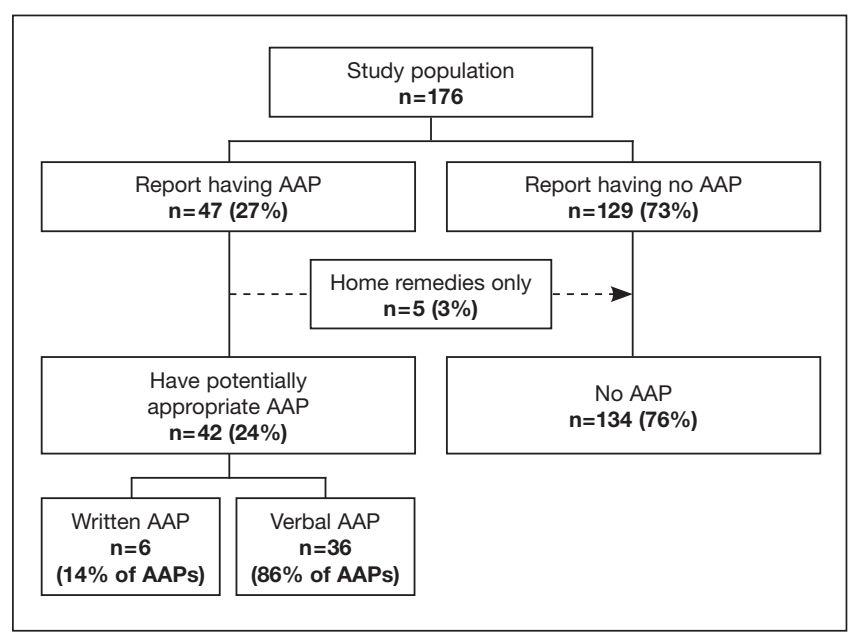

Figure 1) Flow of 176 patients enrolled in two prospective studies in the emergency department and their reported asthma action plans (AAP)

agents (31\% versus 12\%, adjusted OR [aOR] 3.0 [95\% CI 1.14 to 8.07 ) and asthma education (47\% versus 21\%, aOR 3.2 [95\% CI 1.13 to 9.19]) were independently associated with self-report of an AAP. The c-statistic for the final multivariable model was 0.72 .

\section{DISCUSSION}

Despite good evidence for the effectiveness of AAPs (particularly written versus verbal) to abort or mitigate relapses, only one-quarter of patients who were treated and discharged from the ED for asthma exacerbations reported having one in the present study. Moreover, most of these were verbal AAPs; only $3 \%$ of patients had a written AAP. While research confirms that written AAPs are effective, verbal AAPs are not definitively associated with improved asthma outcomes (15).

Despite reporting an AAP, many patients used ineffective interventions as their first-and second-line treatments for loss of asthma control. This represents an important care gap and that could be related to a potential knowledge gap from the health provider and/or patient perspectives (eg, misperception of appropriateness) or a failure to follow instructions. Variations in both the content and structure of available AAPs could also be barriers to their delivery, uptake and make the comparison of their effectiveness difficult (20). Finally, because the most effective therapy in any AAP involving early increased use of anti-inflammatory agents were never reportedly used, the effectiveness of these AAPs would be lower than found in the published literature $(16,17)$.

Patients with an AAP appeared to have more chronic and severe asthma. For example, they had more formal asthma education, more previous ED visits for acute asthma, more previous admissions to the ICU and greater use of ICS or ICS/LABA agents. In adjusted analyses, however, only the use of either ICS or ICS/LABA combination agents and asthma education were significantly associated with self-report of an AAP. As such, it is likely that they may have had more health care encounters, been more often exposed to education and have been instructed in escalating controller therapy more often than those with milder disease.

Nonetheless, few of the patients with AAPs used effective strategies such as Symbicort Maintenance and Reliever Therapy (SMART [AstraZeneca Canada Inc]), quadrupling or quintupling preventer (ICS) therapy, starting systemic corticosteroids or using formal monitoring strategies (5). Consequently, no patients in the present study used what would be considered to be current best-evidence as part of a written AAP. To be fair, many physicians may still be promoting old, ineffective strategies such as 'double for trouble'; however, we were unable to verify this hypothesis in the present study.
TABLE 4

Asthma action plans (AAPs) of patients presenting to and discharged from the emergency department (ED) for asthma exacerbations $(n=42)$

\begin{tabular}{|c|c|c|c|}
\hline \multirow[b]{2}{*}{ Action } & \multirow[b]{2}{*}{$\begin{array}{l}\text { All, } \\
\text { n (\%) }\end{array}$} & \multicolumn{2}{|c|}{ AAP, $n$} \\
\hline & & $\begin{array}{l}\text { Written } \\
(n=6)\end{array}$ & $\begin{array}{l}\text { Verbal } \\
(n=36)\end{array}$ \\
\hline Increase medication as first step & $27(64.3)$ & 4 & 23 \\
\hline Increase medication as second step & $8(19.1)$ & 1 & 7 \\
\hline Increase SABA alone & $12(28.5)$ & 1 & 11 \\
\hline Increase ICS alone & $3(7.1)$ & 0 & 3 \\
\hline Increase both ICS and SABA & $20(47.6)$ & 4 & 16 \\
\hline Medication increase not specified & $8(19.0)$ & 1 & 7 \\
\hline Double/triple ICS dose & $4(9.5)$ & 1 & 3 \\
\hline Quadruple/quintuple ICS dose & $0(0)$ & - & - \\
\hline Seek medical attention as first step & $8(19.0)$ & 2 & 6 \\
\hline Seek medical attention as second step & $8(19.0)$ & 1 & 7 \\
\hline Only seek medical attention & $7(16.7)$ & 1 & 6 \\
\hline Home remedies as first step & $12(28.6)$ & 0 & 12 \\
\hline Home remedies as second step & $4(9.5)$ & 1 & 3 \\
\hline Home remedies alone & $5(11.5)$ & 0 & 5 \\
\hline $\begin{array}{l}\text { Increase medication then seek medical } \\
\text { help }\end{array}$ & $8(19.0)$ & 1 & 7 \\
\hline Patients with AAP based on peak flow & $1(2.4)$ & 0 & 1 \\
\hline $\begin{array}{l}\text { Patients report using AAP before ED } \\
\text { visit }\end{array}$ & 35 (83.3) & 6 & 29 \\
\hline $\begin{array}{l}\text { Action reported did not match AAP } \\
\text { described }\end{array}$ & $32 / 35(91.4)$ & 5 & 27 \\
\hline
\end{tabular}

ICS Inhaled corticosteroids; SABA Short-acting $\beta$-agonist

Of note - and particular concern - was the uptake of written AAPs in our study, which was lower than proportions reported by studies involving patients not presenting to the $\mathrm{ED}$ with an acute episode of asthma $(14,16,17,22,23)$. A possible reason for this finding is that patients presenting to ED represent a poorly controlled subset of the general asthma population. This subset may be less likely to use effective self-management techniques for their chronic disease. Alternatively, while similar to the provincial averages, their access to primary or specialist care may have been restricted due to cultural or socioeconomic issues (24). Finally, we were unable to find evidence that the treating ED physicians discussed or provided an AAP to any patients. Despite the fact that the ED encounter represents a 'teachable moment', it appears that AAPs are not part of current recommendations of emergency physicians.

Our results point to a significant care gap in asthma knowledge and management in patients presenting to the ED with asthma exacerbations, and supports the urgent need for ED-directed evidence-based and cost-effective interventions to restore asthma control and improve AAP uptake in the ambulatory care setting (21). Strategies, such as early referral to a nurse educator, respiratory therapist or PCP, for the establishment of a personalized AAP could be the focus of future research.

\section{Limitations}

There are several limitations to the present study that warrant discussion. First, our analyses were focused on the comparison between having any AAPs (either written or verbal) and having no AAP. While the comparison between written AAPs and nonwritten AAPs may have been informative, our quantitative and qualitative analytic choices were driven by our interest in exploring AAP possession and usage despite their appropriateness; the low event rate (3\% having written AAPs) precluded us from comparing subjects who reported 
having written versus not having written AAPs. Second, given that the present study was a secondary analysis, AAP details were not the main focus of the primary studies. To ensure comprehensive data and accuracy, every baseline questionnaire used in compiling the information for the present study was double-checked. In addition, when needed, we used access to electronic health records and hospital charts to complete information required for our analysis. Third, the sample size was relatively small; however, given the compelling results, additional patients in the sample would be unlikely to materially change the results. Fourth, the present study was conducted in one Canadian centre; therefore, the generalizability of the results to other centres and jurisdictions may be a concern. Compared with previous studies, however, our patient population had similar sociodemographic characteristics, asthma severity and eligibility criteria for enrollment; therefore, we do not believe this is a substantive issue (25-27). Fifth, we excluded admitted patients and those cared for by specialists (eg, respirologists, general internists) because we anticipated their access to education and AAPs would be guaranteed. Finally, we did not examine admitted patients, patients with mixed asthma-chronic obstructive pulmonary disease and those with complicated presentations, perhaps also limiting the external validity of our findings.

\section{CONCLUSION}

Despite high-quality evidence supporting their use, uptake of written AAPs remains very low in asthma patients presenting to EDs with acute exacerbations. Even when patients have an AAP, their strategies to prevent an ED visit are either not used or clinically ineffective. Strategies to improve the understanding, uptake and early self-activation of valid AAPs during a loss of asthma control are urgently needed to avoid or mitigate ED visits and reduce the burden of disease in this at-risk population.

\section{REFERENCES}

1. Hodder R, Lougheed MD, Rowe BH, FitzGerald JM, Kaplan AG, McIvor RA. Management of acute asthma in adults in the emergency department: Nonventilatory management. CMAJ 2010;182:E55-67.

2. Prevalence of Asthma. Statistics Canada, Asthma, 2010. <www.statcan.gc.ca/pub/82-003-x/2008002/article/10551-eng.pdf> (Accessed December 16, 2013).

3. Emerman CL, Woodruff PG, Cydulka RK, Gibbs MA, Pollack CV Jr, Camargo CA Jr. Prospective multicenter study of relapse following treatment for acute asthma among adults presenting to the emergency department. MARC Investigators. Multicenter Asthma Research Collaboration. Chest 1999;115:919-27.

4. Rowe BH, Villa-Roel C, Sivilotti ML, et al. Relapse after emergency department discharge for acute asthma. Acad Emerg Med 2008;15:709-17.

5. Lougheed MD, Lemiere C, Ducharme FM, et al; for the Canadian Thoracic Society Asthma Clinical Assembly. Canadian Thoracic Society 2012 guideline update: Diagnosis and management of asthma in preschoolers, children and adults. Can Respir J 2012;19:127-64.

6. The Global Strategy for Asthma Management and Prevention, Global Initiative for Asthma (GINA) 2011. <www.ginasthma.org> (Accessed September 8, 2014).

7. British Thoracic Society Scottish Intercollegiate Guidelines Network. British Guideline on the Management of Asthma. Thorax 2008;63(Suppl 4):iv1-121.

8. National Asthma Education Prevention Program. Expert Panel Report 3 (EPR-3): Guidelines for the diagnosis and management of asthma - summary report 2007. J Allergy Clin Immunol 2007;120:S94-138.

9. Meyer SB, Bell AD, Kaplan AG, Kim H, McIvor RA. Management of asthma in adults. CMAJ 2009;181:915-22.

10. Partridge MR, Hill SR. Enhancing care for people with asthma: The role of communication, education, training and selfmanagement. 1998 World Asthma Meeting Education and Delivery of Care Working Group. Eur Respir J 2000;16:333-48.

11. Fishwick D, D'Souza W, Beasley R. The asthma self-management plan system of care: What does it mean, how is it done, does it
ACKNOWLEDGEMENTS: Brian H Rowe wrote the study protocol and was responsible for the general coordination of the study; EC and SC were responsible of de-identifying study data, appending databases and checking for consistency using the original data sources; EC also drafted the final manuscript; CVR participated in the analysis/interpretation of data and contributed to the final manuscript; SRM, MB and RJR supported the design of the study and made substantial contributions to the final manuscript. All authors reviewed and approved the final version of the manuscript for publication.

FUNDING: Funding for this study was provided by the Emergency Medicine Research Group (EMeRG) in the Department of Emergency Medicine at the University of Alberta (Edmonton, Alberta). The authors thank Diane Milette for her secretarial support. Elfriede Cross received a summer studentship from Alberta Innovates Health Solutions (AIHS; formerly known as the Alberta Heritage Foundation in Edmonton, Alberta). Dr Villa-Roel is supported by Canadian Institutes of Health Research (CIHR) in partnership with the Knowledge Translation Branch (Ottawa, Ontario). Dr Majumdar is an AIHS Health Scholar and holds the Endowed Chair in Patient Health Management from the Faculties of Medicine and Dentistry and Pharmacy and Pharmaceutical Sciences, University of Alberta. Dr Rosychuk is supported by AIHS as a Health Scholar. Dr Rowe's research is supported by CIHR through a Tier I Canada Research Chair in Evidence-based Emergency Medicine (Ottawa, Ontario).

DISCLOSURES: The authors have no financial disclosures or conflicts of interest to declare.

INSTITUTION FROM WHICH THE WORK ORIGINATED: University of Alberta, Edmonton, Alberta.

work, what models are available, what do patients want and who needs it? Patient Educ Couns 1997;32:S21-33.

12. Gibson PG, Powell H. Written action plans for asthma: An evidence-based review of the key components. Thorax 2004;59:94-9.

13. Gibson PG, Powell H, Coughlan J, et al. Self-management education and regular practitioner review for adults with asthma. Cochrane Database Syst Rev 2003:CD001117.

14. Patel MR, Valerio MA, Sanders G, Thomas LJ, Clark NM. Asthma action plans and patient satisfaction among women with asthma. Chest 2012;142:1143-9.

15. Abramson MJ, Bailey MJ, Couper FJ, et al; and the Victorian Asthma Mortality Study Group. Are asthma medications and management related to deaths from asthma? Am J Respir Crit Care Med 2001;163:12-8.

16. Beauchesne MF, Levert V, El Tawil M, Labrecque M, Blais L. Action plans in asthma. Can Respir J 2006;13:306-10.

17. Camargo CA Jr, Reed CR, Ginde AA, Clark S, Emond SD, Radeos MS. A prospective multicenter study of written action plans among emergency department patients with acute asthma. J Asthma 2008;45:532-8.

18. Fitzgerald JM, Boulet L-P, McIvor RA, Zimmerman S, Chapman KR. Asthma control in Canada remains suboptimal: The reality of asthma control (TRAC) study. Can Respir J 2006;13:253-9.

19. Boulet LP, Devlin H, O'Donnell DE. The Physicians' Practice Assessment Questionnaire on asthma and COPD. Respir Med 2011;105:8-14.

20. Gupta S, Wan FT, Ducharme FM, Chignell MH, Lougheed MD, Straus SE. Asthma action plans are highly variable and do not conform to best visual design practices. Ann Allergy Asthma Immunol 2012;108:260-5,e2.

21. Rowe BH, Majumdar SR. Improving quality of asthma care after emergency department discharge: Evidence before action. Ann Emerg Med 2005;45:299-301.

22. Chandra D, Clark S, Camargo CA Jr. Race/ethnicity differences in the inpatient management of acute asthma in the United States. Chest 2009;135:1527-34. 


\section{Cross et al}

23. Chapman KR, Boulet LP, Rea RM, Franssen E. Suboptimal asthma control: Prevalence, detection and consequences in general practice. Eur Respir J 2008;31:320-5.

24. Sin DD, Wells H, Svenson LW, Man SF. Asthma and COPD among aboriginals in Alberta, Canada. Chest 2002;121:1841-6.

25. Zeiger RS, Heller S, Mellon MH, Wald J, Falkoff R, Schatz M. Facilitated referral to asthma specialist reduces relapses in asthma emergency room visits. J Allergy Clin Immunol 1991;87:1160-8.
26. Cowie RL, Revitt SG, Underwood MF, Field SK. The effect of a peak flow-based action plan in the prevention of exacerbations of asthma. Chest 1997;112:1534-8.

27. Levy ML, Robb M, Allen J, Doherty C, Bland JM, Winter RJ. A randomized controlled evaluation of specialist nurse education following accident and emergency department attendance for acute asthma. Respir Med 2000;94:900-8. 


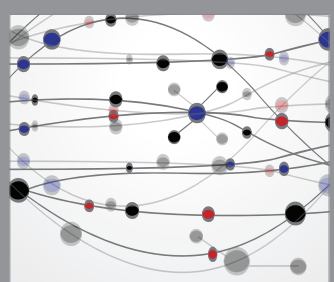

The Scientific World Journal
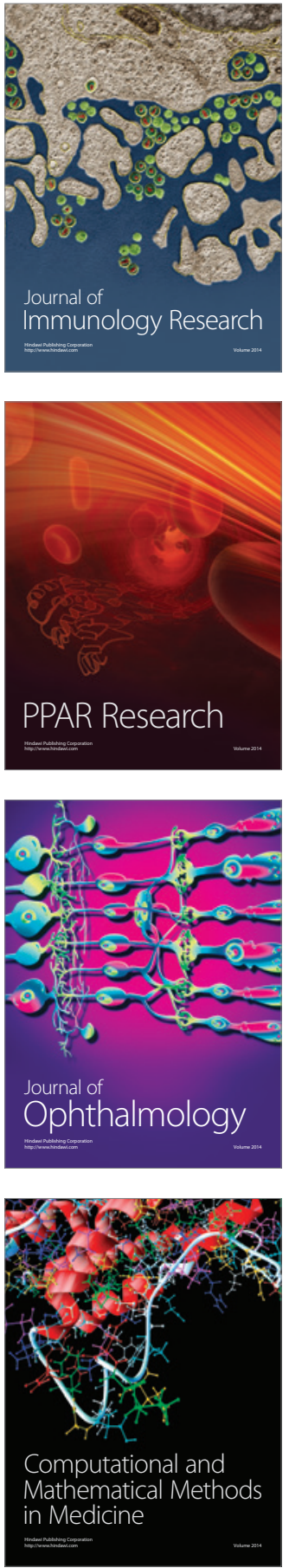

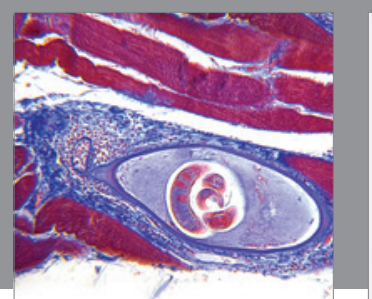

Gastroenterology Research and Practice

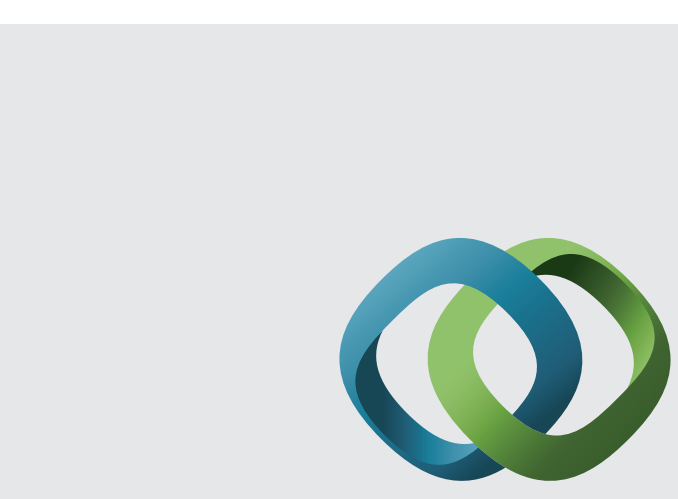

\section{Hindawi}

Submit your manuscripts at

http://www.hindawi.com
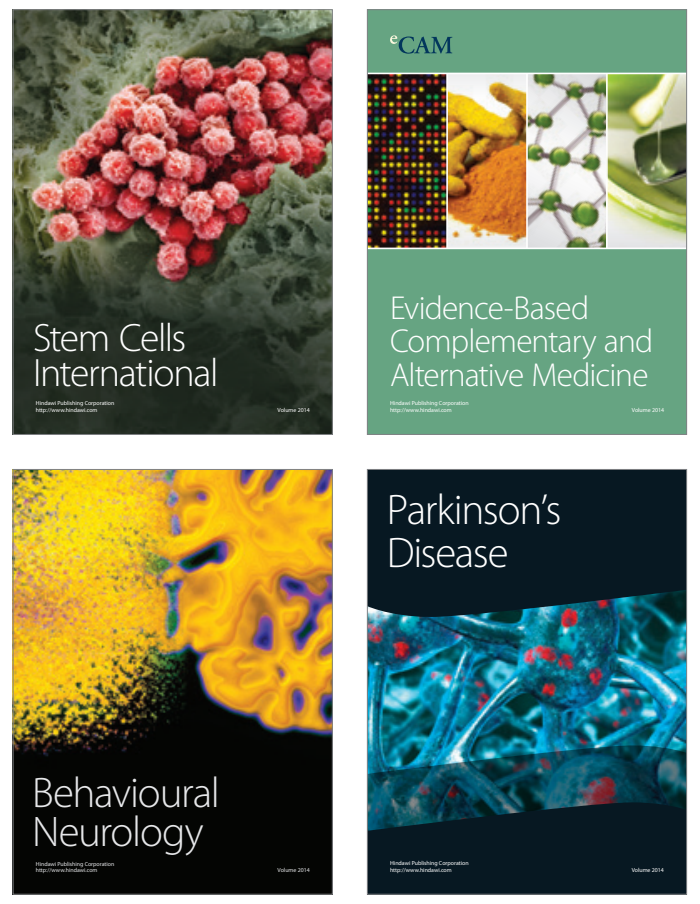
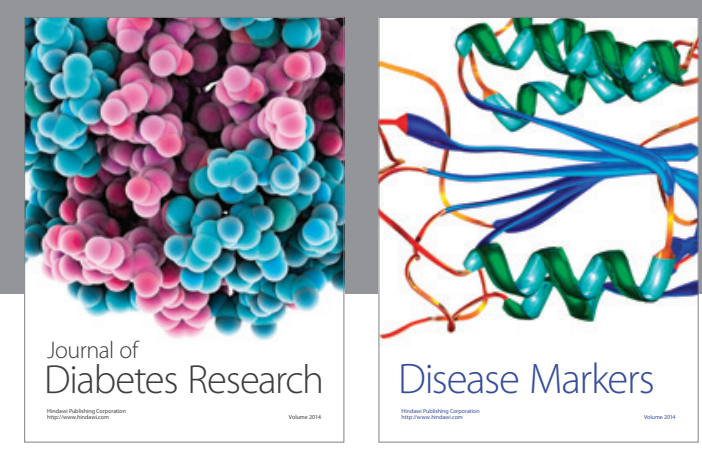

Disease Markers
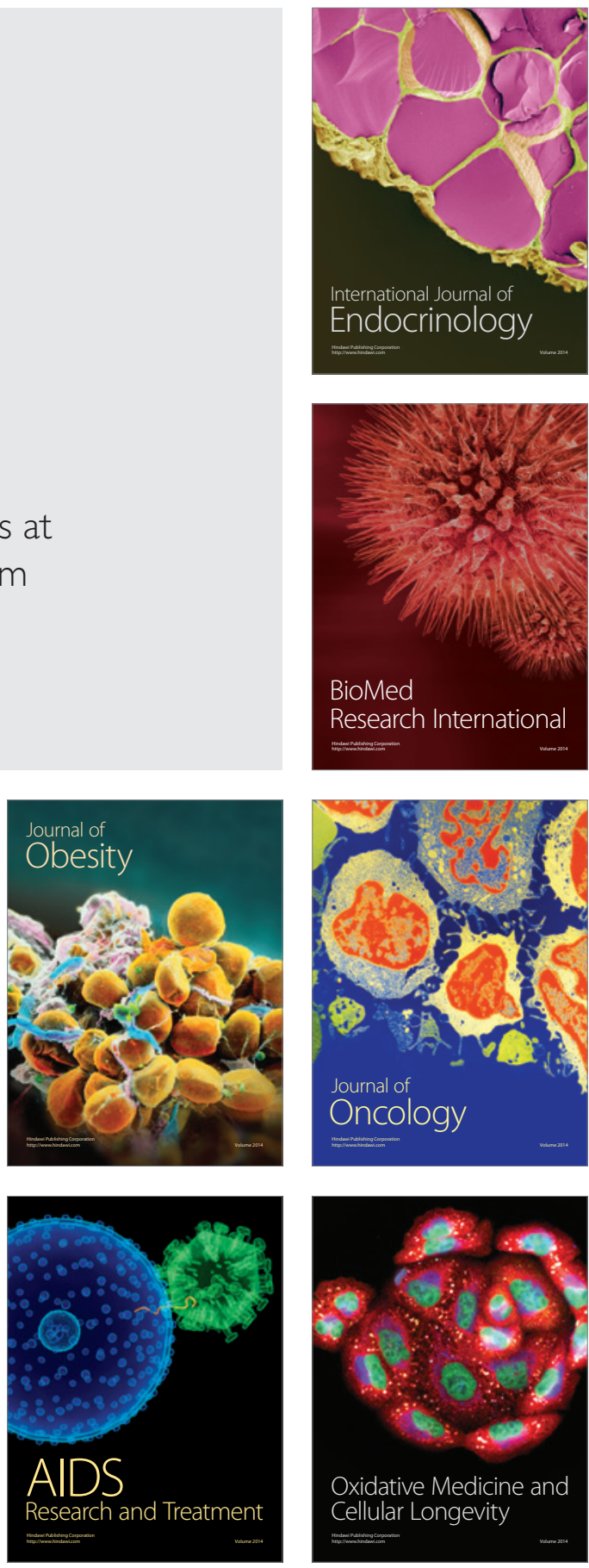